\title{
Rheumatic aortic stenosis in young patients presenting with combined aortic and mitral stenosis
}

\author{
G. VIJAYARAGHAVAN, GEORGE CHERIAN, S. KRISHNASWAMI, \\ I. P. SUKUMAR, AND STANLEY JOHN
}

From the Departments of Cardiology and Cardiothoracic Surgery, Christian Medical College and Hospital, Vellore, S. India

This report describes 30 patients under the age of 30 years with rheumatic aortic stenosis, presenting with combined aortic and mitral stenosis. Three patients had additional tricuspid stenosis. Twenty-eight patients gave a history of rheumatic polyarthritis. The diagnosis was confirmed by right and left heart catheterisation in all. The murmur of aortic stenosis was not initially present in 8 out of 10 patients in congestive heart failure. Aortic valve calcification was not seen. Cineangiography showed a tricuspid aortic valve in all, unlike congenital aortic stenosis. A unique feature of this group was the raised pulmonary vascular resistance in 87 per cent of the patients. The present study shows that patients in India developing aortic stenosis after rheumatic fever do so early in the natural history of the disease.

Rheumatic heart disease is well known to be the main cardiac disease in India (Hughes and Yusuf, 1930; Mathur, 1960; Padmavathy and Datey, 1970). There are differences between rheumatic heart disease as seen in India and as reported from Western countries. In India, isolated severe rheumatic mitral stenosis occurs in a much younger age-group and about 30 per cent of mitral valvotomies are done in patients below the age of 20 (Roy et al., 1963; Cherian et al., 1964; Shah, 1974). Much has been written about juvenile mitral stenosis in India (Vytilingam et al., 1970) and in countries like Sri Lanka (Paul, 1967), Thailand (Jumbala et al., 1970), Turkey (Ozcan et al., 1970), and Israel (Borman et al., 1961), but there have been no reports describing the occurrence of rheumatic stenosis of the aortic valve in the younger age-group. This may partly be the result of the

Table 1 Rheumatic aortic stenosis in young patients

\begin{tabular}{llcl}
\hline & $\begin{array}{l}\text { No. of cases } \\
\text { reported }\end{array}$ & $\begin{array}{l}\text { No. of cases } \\
\text { below 30 years }\end{array}$ & $\%$ \\
\hline Katznelson et al. (1960) & 22 & $\mathrm{Nil}$ & 0 \\
Honey (1961) & 35 & 2 & $5 \cdot 7$ \\
Reid et al. (1962) & 15 & 1 & $6 \cdot 6$ \\
Zitnik et al. (1965) & 10 & $\mathrm{Nil}$ & 0 \\
Schattenberg et al. (1967) & 35 & 3 & $8 \cdot 5$ \\
Present series (1976) & 50 & 30 & 60 \\
\hline
\end{tabular}

Received for publication 8 July 1976 difficulty in differentiating rheumatic aortic stenosis from congenital aortic stenosis without aortography. On reviewing the published reports on combined aortic and mitral stenosis (Table 1) we find that most of the patients were above the age of 30 years. The present report is based on a study of 30 patients below 30 years with combined aortic and mitral stenosis.

\section{Subjects and methods}

During the past 5 years (1970-1975) we have had 50 patients with combined aortic stenosis and mitral stenosis, of whom 30 were below the age of 30 years. Patients were drawn from all over India.

After a detailed clinical history had been obtained a complete physical examination was made. All patients had a posteroanterior chest $x$-ray film and a right anterior oblique film with barium in the oesophagus; fluoroscopy with an image intensifier was used to detect mitral and aortic valvar calcification. Later, all patients had right and left heart catheterisation studies under light sedation using phenobarbitone and promethazine hydrochloride. Pressures were recorded using a Statham P23 Db pressure transducer connected to an Electronics for Medicine 8 Channel photographic recorder. Simultaneous pulmonary artery wedge and left ventricular pressure records were obtained in 20 patients. The remaining 10 patients had transeptal left atrial 
Table 2 Interval between first attack of rheumatic fever and onset of symptoms

\begin{tabular}{lll}
\hline No. of years & No. of patients & $\%$ \\
\hline$<2$ & Nil & 0 \\
$2-5$ & 3 & $10 \cdot 7$ \\
$6-10$ & 6 & $21 \cdot 4$ \\
$11-20$ & 17 & $60 \cdot 7$ \\
$>20$ & 2 & $7 \cdot 2$ \\
\hline
\end{tabular}

catheterisation, with simultaneous recording of left atrial and left ventricular pressures. The aortic valve gradient was measured in 15 patients on a withdrawal record from left ventricle to aorta; simultaneous left ventricular and aortic pressure recordings were used in the remaining 15 patients, the left ventricle being entered in 10 by transeptal catheterisation, and in 5 by direct left ventricular puncture. Cardiac output was calculated using the Fick principle.

\section{Results and analysis}

\section{AGE AND SEX INCIDENCE}

Ages varied from 15 to 30 years. Twelve patients were between 10 and 20 years, and 18 were between 21 and 30 years. There were 23 male and 7 female patients.

\section{HISTORY OF RHEUMATIC FEVER}

Twenty-eight patients (93\%) gave a history of migratory polyarthritis in childhood, suggestive of rheumatic fever. One patient had only a single attack, while all the others had recurrent attacks. None gave a history of chorea or rheumatic skin manifestations. The interval between the first attack of rheumatic fever and onset of dyspnoea on effort is shown in Table 2. The shortest interval was 5 years.

\section{PRESENTING SYMPTOMS}

These are shown in Table 3. All patients complained of exertional dyspnoea. This was grade 1 in 1 patient, grade 2 in 14, grade 3 in 11, and grade 4 in 4 patients. Four patients gave a history of recurrent paroxysmal nocturnal dyspnoea. Angina on effort

Table 3 Presenting symptoms

\begin{tabular}{lrr}
\hline & No. of patients & $\%$ \\
\hline Dyspnoea & 30 & 100 \\
Palpitation on exertion & 15 & 50 \\
Angina on effort & 11 & 36 \\
Haemoptysis & 4 & 13 \\
Syncope & 2 & 6 \\
Dependent oedema & 10 & 33 \\
\hline
\end{tabular}

was present in 11 patients. Ten patients were in congestive heart failure.

\section{PHYSICAL SIGNS}

The arterial pulse was not anacrotic in any of our patients, but the pulse volume was small in 26 and increased by associated aortic regurgitation in 4 . Cardiomegaly was present in 28 patients, and was massive in 3. A powerful apical impulse was seen and felt in 13 patients, while in another 15 the impulse was tapping in nature with a palpable shock of a loud first sound and a diastolic thrill. A systolic thrill was felt in the aortic area in 16 patients; in most instances, this thrill was faint and felt only in expiration with the patient leaning forward. A left parasternal heave was present in 27 patients. All the patients had an accentuated pulmonary closure sound, and 17 had palpable pulmonary artery pulsations and a palpable pulmonary closure sound. Aortic closure was soft in 15 patients. A clear mitral opening snap was audible in 24 patients and an aortic ejection click in 10; both an ejection click and an opening snap were present only in 4 patients. A full length mitral diastolic murmur was present in all except 3 , one of whom had only a mid-diastolic murmur, the other 2 having no mitral diastolic murmur at all. Twelve patients had apical systolic murmurs. An ejection systolic murmur in the aortic area was audible in 28 patients; in 8 out of the 10 patients with congestive cardiac failure, the murmur was heard only after this had been controlled. In the other 2 patients aortic stenosis was diagnosed only at cardiac catheterisation. A soft blowing early diastolic murmur at the left sternal border was a common finding, and was heard in $\mathbf{2 2}$ of our patients; this was proved to be due to aortic regurgitation by angiography. Ten patients were in congestive heart failure. In 3 of these, it was not possible to control the cardiac failure adequately; the jugular venous pressure remained high with prominent $a$ waves, and the presence of associated tricuspid stenosis was confirmed at cardiac catheterisation.

\section{ELECTROCARDIOGRAM}

The electrocardiographic features are shown in Table 4. Left ventricular hypertrophy alone or combined with right ventricular hypertrophy was present in 14 patients. Left ventricular strain pattern was present in 10 patients.

\section{RADIOLOGICAL FEATURES}

Cardiomegaly was present in all the 30 patients. It was mild in 12, moderate in 12, and severe in 6 patients; the cardiac silhouette seldom showed a distinct left or right ventricular contour. Left atrial 
enlargement was present in all the 30 patients. Post-stenotic dilatation of the aorta was present in 8 cases. The main pulmonary artery was dilated and prominent in 23 patients, but peripheral pruning of the pulmonary vessels was seen in 2 only. Dilated upper lobe veins were seen in 20 patients and in 8 of these there was hilar clouding; septal lines were present in 6 cases. Fluoroscopy revealed mitral valve calcification in 5 patients, but aortic valve calcification was not seen in any.

HAEMODYNAMIC FEATURES (Table 5)

Cardiac index varied from 1.4 to $4.21 / \mathrm{min}$ per $\mathrm{m}^{2}$, and was low in 16 patients. Right atrial pressure was raised in 14 patients and conspicuously so (more than $10 \mathrm{mmHg}$ mean pressure) in the 10 patients who were in congestive heart failure; three of these had a significant end-diastolic gradient (more than $3 \mathrm{mmHg}$ ) across the tricuspid valve when right atrial and right ventricular pressures were recorded simultaneously.

Nine patients had mild pulmonary hypertension (mean pulmonary artery pressure 25 to $50 \%$ of systemic pressure); 15 patients had moderate pulmonary hypertension (mean pulmonary artery pressure 50 to $75 \%$ of systemic pressure); 6 patients had severe pulmonary hypertension (mean pulmonary artery pressure more than $75 \%$ of systemic pressure), and 2 of these had systemic pressures in the pulmonary artery. Pulmonary vascular resistance was raised in 26 subjects (Table 5), and was more than 5 units in 18 patients. The mean direct or indirect left atrial pressure ranged from 14 to $45 \mathrm{mmHg}$; and was above $25 \mathrm{mmHg}$ in 17 patients; direct left atrial pressure was below $15 \mathrm{mmHg}$ in 2 patients, both of whom had a cardiac index below $2.01 / \mathrm{min}$ per $\mathrm{m}^{2}$. The end-diastolic gradient across the mitral valve ranged from 8 to $35 \mathrm{mmHg}$; in 4 subjects it was less than $10 \mathrm{mmHg}$ and in 14 above $20 \mathrm{mmHg}$. The peak-to-peak systolic gradient between left ventricle and aorta varied from 15 to $90 \mathrm{mmHg}$, and was less than $20 \mathrm{mmHg}$ in one patient, between 20 and $50 \mathrm{mmHg}$ in 19, and more than $50 \mathrm{mmHg}$ in 10 patients. The three patients with the highest aortic systolic gradients $(80,90$, and $130 \mathrm{mmHg}$ ) had relatively small end-diastolic gradients across the mitral valve (14, 14, and $20 \mathrm{mmHg}$ ).

\section{CINEANGIOGRAPHIC FINDINGS}

Left ventriculography showed a small cavity in 10 patients. A persistent intact crescent of the stenotic mitral valve in diastole was visible in 20 patients. Trivial mitral regurgitation was present in 6 patients (mild mitral regurgitation in 4). In all the 10 patients who had left atrial angiography, a per-
Table 4 Electrocardiographic features

\begin{tabular}{lcc}
\hline & $\begin{array}{c}\text { No. of } \\
\text { patients }\end{array}$ & $\%$ \\
\hline Sinus rhythm & 21 & 69 \\
Atrial fibrillation & 9 & 31 \\
Left and right atrial enlargement & 4 & 13 \\
Left atrial enlargement only & 4 & 13 \\
Left and right ventricular hypertrophy & 4 & 13 \\
Right ventricular hypertrophy only & 2 & 6.6 \\
Left ventricular hypertrophy only & 10 & 33 \\
Right axis deviation only & 2 & 6.6 \\
& & \\
\hline
\end{tabular}

sistent diastolic crescent of the mitral valve, persistent contrast gradient from the left atrium to left ventricle, and doming of the stenotic mitral valve were seen. Aortography showed a tricuspid aortic valve in all patients; aortic regurgitation of varying degree was present in 25 patients (trivial in 15 and mild in 10).

\section{Discussion}

The combination of aortic stenosis and mitral stenosis occurs in about 5 per cent of patients after rheumatic fever (Uricchio et al., 1959; Katznelson et al., 1960). The aortic stenosis usually makes its appearance 15 to 20 years after an episode of rheumatic carditis. Hence, rheumatic aortic stenosis is often diagnosed only in the fourth or fifth decade of life (Katznelson et al., 1960; Honey, 1961; Zitnik et al., 1965). In the younger age-group, aortic stenosis is usually considered congenital unless otherwise proved. Rheumatic aortic stenosis was diagnosed in our patients because of the history of rheumatic fever, the associated mitral stenosis, and the tricuspid aortic valve. A history of rheumatic fever was obtained in only 53 per cent of our patients with isolated mitral stenosis, while 93 per

Table 5 Haemodynamic features

\begin{tabular}{llll}
\hline Cardiac index (C1) & l/min per $m^{2}$ & $\begin{array}{l}\text { No. of } \\
\text { patients }\end{array}$ & $\%$ \\
\hline & $<2 \cdot 0$ & 6 & 20 \\
& $2 \cdot 0-2 \cdot 8$ & 10 & 33 \\
& $2 \cdot 8$ & 14 & 47 \\
\hline Pulmonary vascular & Units $\times m^{2 \star}$ & No. of & $\%$ \\
resistance & & patients & \\
\hline & $<3$ & 4 & 13 \\
& $3-5$ & 8 & 27 \\
& $5-10$ & 14 & 47 \\
& 10 & 4 & 13 \\
\hline
\end{tabular}

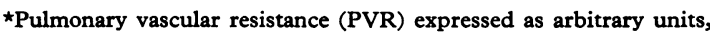
corrected for body surface area

$$
\text { PVR }=\frac{\mathbf{P}_{\mathbf{P A}}-\mathbf{P}_{\text {LA }}}{\mathbf{C I}}
$$


cent of this series gave a history of rheumatic fever. The more striking feature was the history of recurrent polyarthritis in $27(90 \%)$ of these patients. A similar history was obtained in only 12 per cent with isolated rheumatic mitral stenosis (Cherian et al., 1964). Pomerance (1972), in a study of 111 hearts from patients with aortic stenosis, did not find a single case of congenital aortic stenosis with a tricuspid valve. Similarly, Roberts (1970), in a study of the pathological anatomy of stenosed aortic valves, believed that it was reasonable to conclude that the aetiology was rheumatic when aortic stenosis with a tricuspid valve was associated with anatomical disease of the mitral valve. Calcification in rheumatic aortic valve stenosis is also said to be unusual and late, in contrast with congenital aortic stenosis (Aberdeen, 1969). Hence, we take the view that the aetiology of the aortic stenosis in our patients is rheumatic and not congenital.

The recognition of aortic stenosis in patients with mitral stenosis is not always easy (Katznelson et al., 1960), but is important when selecting patients for closed valvotomy (Morrow et al., 1962; Vytilingam et al., 1964). The aortic systolic murmur in these patients is quieter and in 2 of our cases was absent. In 8 others admitted with congestive heart failure and low cardiac output, the aortic murmur was audible only after control of the cardiac failure and an increase in the cardiac output. Uricchio and Likoff (1957) and Honey (1961) have described patients with 'silent' aortic stenosis in whom, after mitral valvotomy, left ventricular enlargement and auscultatory features of aortic stenosis became obvious. Honey (1961) commented that in patients with combined aortic and mitral stenosis, the low cardiac output of severe mitral stenosis results in a low aortic valve gradient and only modest increases in left ventricular systolic pressure. This explains the rarity of left ventricular hypertrophy, angina, and post-stenotic dilatation of aorta in these patients. Moreover, the haemodynamic stresses on this deformed valve are less and, hence, calcification of the aortic valve also occurs rarely.

Development of severe mitral stenosis antedates that of aortic stenosis and the clinical picture is nearly always dominated by features of tight mitral stenosis and pulmonary hypertension. Two of our patients had closed mitral valvotomy performed 6 and 8 years before the present admission to hospital and aortic stenosis was not then detected clinically or at operation. We presume that this lesion developed later, concurrently with mitral restenosis.

Pulmonary hypertension has not been reported as a common sequel of this combination of valve lesions but $18(60 \%)$ of our patients had significant rises in pulmonary vascular resistance ( $>5$ units). Honey (1961), in a study of 35 patients with combined aortic stenosis and mitral stenosis, found only 5 patients $(14 \%)$ with raised pulmonary vascular resistance. In the largest reported series with this combination (141 cases) the mean pulmonary artery pressures ranged from 25 to $32 \mathrm{mmHg}$ and a marked elevation of mean pressure $(40 \mathrm{mmHg}$ or higher) was not observed. The pulmonary vascular resistance ranged from 1.4 to 5.8 units (Uricchio et al., 1959). On the other hand, our patients were prone to develop pulmonary vascular disease at an early age, presumably as a result of the early development of important mitral stenosis.

The present study shows that rheumatic aortic stenosis, like rheumatic mitral stenosis, occurs at a much earlier age in Indian than in Western patients. The reasons for this are not clear. Apart from the different host and environmental factors, it is interesting that 27 of the 30 patients gave a history of recurrent migratory polyarthritis, while only 1 gave a history of a single episode.

\section{References}

Aberdeen, E. (1969). Aortic valvar disease and left ventricular obstruction. In Medical and Surgical Cardiology, p. 951. Ed. by W. Cleland, J. Goodwin, L. McDonald, and D. Ross. Blackwell Scientific Publications, Oxford and Edinburgh.

Borman, J. B., Stern, S., Shapira, T., Milwidsky, H., and Braun, K. (1961). Mitral valvotomy in children. American Heart fournal, 61, 763.

Cherian, G., Vytilingam, K. I., Sukumar, I. P., and Gopinath, N. (1964). Mitral valvotomy in young patients. British Heart fournal, 26, 157.

Honey, M. (1961). Clinical and haemodynamic observation in combined mitral and aortic stenosis. British Heart fournal, 23, 545.

Hughes, T. A., and Yusuf, M. (1930). Heart disease in the Punjab with special reference to mitral stenosis. Indian fournal of Medical Research, 18, 483.

Jumbala, B., Sukumalchantra, Y., Vichiptan, P., Tongmitr, V., Prachuabmoh, K., and Chatikaranij, K. (1970). Juvenile mitral stenosis in Thailand. In Cardiology: Current Topics and Progress, p. 184. Ed. by M. Eliakim and H. N. Neufeld. Academic Press, London.

Katznelson, G., Jreissaty, R. M., Levinson G. E. Stein, S. W., and Abelmann, W. H. (1960). Combined aortic and mitral stenosis. American fournal of Medicine, 29, 242.

Mathur, K. S. (1960). Problem of heart disease in India. American fournal of Cardiology, 5, 60.

Morrow, A. G., Awe, W. C., and Braunwald, E. (1962). Combined mitral and aortic stenosis. British Heart fournal, 24, 606.

Ozcan, R., Danopulos, D., Dorkew, N., Ozsaruhan, O., Alhan, M. A., and Camli, N. (1970). Severe mitral stenosis under the age of 15. In Cardiology: Current Topics and Progress, p. 177. Ed. by M. Eliakim and H. N. Neufeld. Academic Press, London.

Padmavathy, S., and Datey, K. K. (1970). Epidemiology of cardiovascular disease in India. In Cardiology: Current Topics and Progress, p. 50. Ed. by M. Eliakim and H. N. Neufeld. Academic Press, London. 
Paul, A. T. S. (1967). The problem of mitral stenosis in childhood. Annals of the Royal College of Surgeons of England, 41, 387.

Pomerance, A. (1972). Pathogenesis of aortic stenosis and its relation to age. British Heart Fournal, 34, 569.

Reid, J. M., Stevenson, J. G., Barclay, R. S., and Welsh, T. M. (1962). Combined aortic and mitral stenosis. British Heart fournal, 24, 509.

Roberts, W. C. (1970). The structure of the aortic valve in clinically isolated aortic stenosis. Circulation, 42, 91.

Roy, S. B., Bhatia, M. L., Lazaro, E. J., and Ramalingaswami, V. (1963). Juvenile mitral stenosis in India. Lancet, 2, 1193.

Schattenberg, T. T., Titus, J. L., and Parkin, T. W. (1967). Clinical findings in acquired aortic valve stenosis. Effect of disease of other valves. American Heart fournal, 73, 322.

Shah, S. (1974). Juvenile rheumatic mitral stenosis. Indian Heart Fournal, 26, Supp. 138.

Uricchio, J. F., and Likoff, W. (1957). Effect of mitral commissurotomy on coexisting aortic valve lesions. New England fournal of Medicine, 256, 199.
Uricchio, J. F., Sinha, K. P., Bentivoglio, L., and Goldberg, H. (1959). A study of combined mitral and aortic stenosis. Annals of Internal Medicine, 51, 668.

Vytilingam, K. I., Cherian, G., and Sukumar, I. P. (1970). A study of juvenile mitral stenosis during a 10-year period (1958-1967). In Cardiology: Current Topics and Progress, p. 187. Ed. by M. Eliakim and H. N. Neufeld. Academic Press, London.

Vytilingam, K. I., Cherian, G., Sukumar, I. P., and Gopinath, N. (1964). Closed aortic and mitral valvotomy for combined aortic and mitral stenosis. Indian Heart Fournal, 16, 270.

Zitnik, R. S., Piemme, T. E., Messer, R. J., Reed, D. P., Haynes, F. W., and Dexter, L. (1965). The masking of aortic stenosis by mitral stenosis. American Heart fournal, 69, 22.

Requests for reprints to Dr. George Cherian, Department of Cardiology, C. M. C. Hospital, Vellore 632 004, India. 